\title{
Structural Analysis of the QCM Aboard the ER-2
}

\author{
Phyllis D. Jones, Peter M. Bainum, and Guangqian Xing \\ Dept. of Mechanical Engineering, Howard University, Washington, DC 20059
}

\section{$\underline{\text { Introduction }}$}

As a result of recent supersonic transport (SST) studies on the effect they may have on the atmosphere, several experiments have been proposed to capture and evaluate samples of the stratosphere where SST's travel. One means to achieve this is to utilize the quartz crystal microbalance (QCM) installed aboard the ER-2, formerly the U-2 reconnaissance aircraft. The QCM is a cascade impactor designed to perform in-situ, real-time measurements of aerosols and chemical vapors at an altitude of 60,000- 70,000 feet. The ER-2 is primarily used by NASA for Earth resources to test new sensor systems before they are placed aboard satellites. One of the main reasons the ER-2 is used for this flight experiment is its capability to fly approximately twelve miles above sea level (can reach an altitude of 78,000 feet)[1]. Because the ER-2 operates at such a high altitude, it is of special interest to scientists interested in space exploration or supersonic aircraft. Some of the experiments are designed to extract data from the atmosphere around the ER-2. For the current flight experiment, the QCM is housed in a frame that is connected to an outer pod that is attached to the fuselage of the ER-2. Due to the location of the QCM within the housing frame and the location of the pod on the ER-2, the pod and its contents are subject to structural loads. In addition to structural loads, structural vibrations are also of importance because the QCM is a frequency induced instrument. Therefore, a structural analysis of the instrument within the frame is imperative to determine if resonance and/or undesirable deformations occur.

\section{Structural Analysis}

In order to perform a structural analysis of the QCM within its housing frame, a finite element mathematical model of the system (QCM and housing frame) was created. Initially, separate finite element models of the QCM and housing frame were constructed, Figures I \& II respectively. Once the individual models were produced, they were graphically incorporated to create the system as shown in Figure III. The models were graphically generated by the finite element graphical software package MSC/PATRAN[2]. By inputting the structure's geometry, material properties, inertia, and boundary conditions, MSC/PATRAN has the capabilities to generate a finite element model. The geometry consists of the physical make-up of the structure and its dimensions with respect to a given. origin. For the QCM, the dimensions are length=1 8.3 in., width=4.5 in., and height=4.8 in. and for the housing frame the length=66.5 in., width=1 1.5 in., and height=13.2 in. For this system, both the QCM and housing frame are composed of aluminum with material properties of $10 \mathrm{E} 6 \frac{\mathrm{lbs}}{\mathrm{in}^{2}}$ for Young's modulus, 0.333 for Poisson's ratio, and $0.98 \frac{\mathrm{lbs}}{\mathrm{in}^{3}}$ for the density. The QCM rests lengthwise on an aluminum plate within the frame and is rigidly bounded at both ends, see Figure III. Once the system is graphically generated, the finite element model data is transferred into MSC/NASTRAN which is utilized to generate analytical results, see Table I, based on the data from MSC/PATRAN. After the analytical results are compiled, the results are input back into MSC/PATRAN for further graphical analysis. As an example, the various mode shapes for the system are depicted in Figure IV.

- Research supported by the NASA/Howard University Center for the Study of Terrestrial \& Extraterrestrial Atmospheres (CSTEA) 


\begin{tabular}{|c|c|}
\hline MODE NUMBER & CYCLIC FREQUENCY \\
\hline 1 & 130.159 \\
\hline 2 & 208.456 \\
\hline 3 & 268.106 \\
\hline 4 & 282.352 \\
\hline 5 & 324.958 \\
\hline 6 & 338.102 \\
\hline 7 & 355.453 \\
\hline 8 & 359.442 \\
\hline 9 & 360.811 \\
\hline 10 & 388.971 \\
\hline
\end{tabular}

Table I: Analytical Results

$\underline{\text { Results }}$

The results indicate several of the mode shapes of the system could cause errors in the reading of the QCM, see Figure IV, due to excessive deflections associated with several of the vibrational modes. Within the housing frame, the QCM is supported by an aluminum plate. Certain mode shapes indicate that this plate and the QCM could have large distortions (deflections) which directly effect the readings of the QCM.

The QCM contains quartz crystals which are used to accumulate air sample particulates[3]. Once these samples are collected, the instrument records the change in frequency between the reference crystal and the crystal that collects the air samples. Because the QCM relies on changes in frequency, the deflections could cause interference with these changes in the frequency readings. One means of minimizing or eliminating the deflections would be to attach a vibration absorber (modeled by a) springmass-damper to a specific point(s) on the system where large deflections are occurring[4]. By examining which locations on the system yield the largest deflections that directly affect the QCM, specific nodal point(s) within the system's mathematical model can be chosen as possible points to apply the springmass-damper. By determining from the modal participation factors, points of maximum deflection of the eigenvectors and mode shapes of the system, the nodal points of greatest deflections can be determined to yield the best possible points of application for the spring-mass-damper. Once these nodal point(s) are determined, the spring-mass-damper is mathematically designed and then implemented into MSC/NASTRAN. The analytical results are computed and again the results are input back into MSC/PATRAN to determine if the point(s) of application of the spring-mass-damper are successful. This process is repeated until an optimum design is obtained to minimize or eliminate the deflections.

\section{Acknowledgments}

I would like to acknowledge and thank Mrs. Sandra Irish, the group leader of the Structural Analysis Section at NASA Goddard Space Flight Center, Greenbelt, MD, for all of her help and time in assistance with this project.

\section{$\underline{\text { References }}$}

[1] Stewart, Doug, "Above the Sky”, Air \& Space, August/September 1993, pp. 11-13.

[2] Miller, Mark, User's Guide: Getting Started With MSC/NASTRAN, Ist Ed., MacNeal Schwendler Corp., Los Angeles, CA, December 1993.

[3] Jones, Phyllis D., "Description of the QCM/SAW Utilized for the Concorde/ER-2 Flight Experiment", Technical Note, Dept. of Aerospace Engineering Sciences, University of Colorado, Boulder, CO, August 1994.

[4] Marsis, Wisjnu \& Bainum, Peter, "Hybrid Control System for Space Mast Structures", AAS/AIAA Astrodynamics Specialist Conference, Durango, CO, August 19-22, 1991 Paper No. AAS -91-374. 


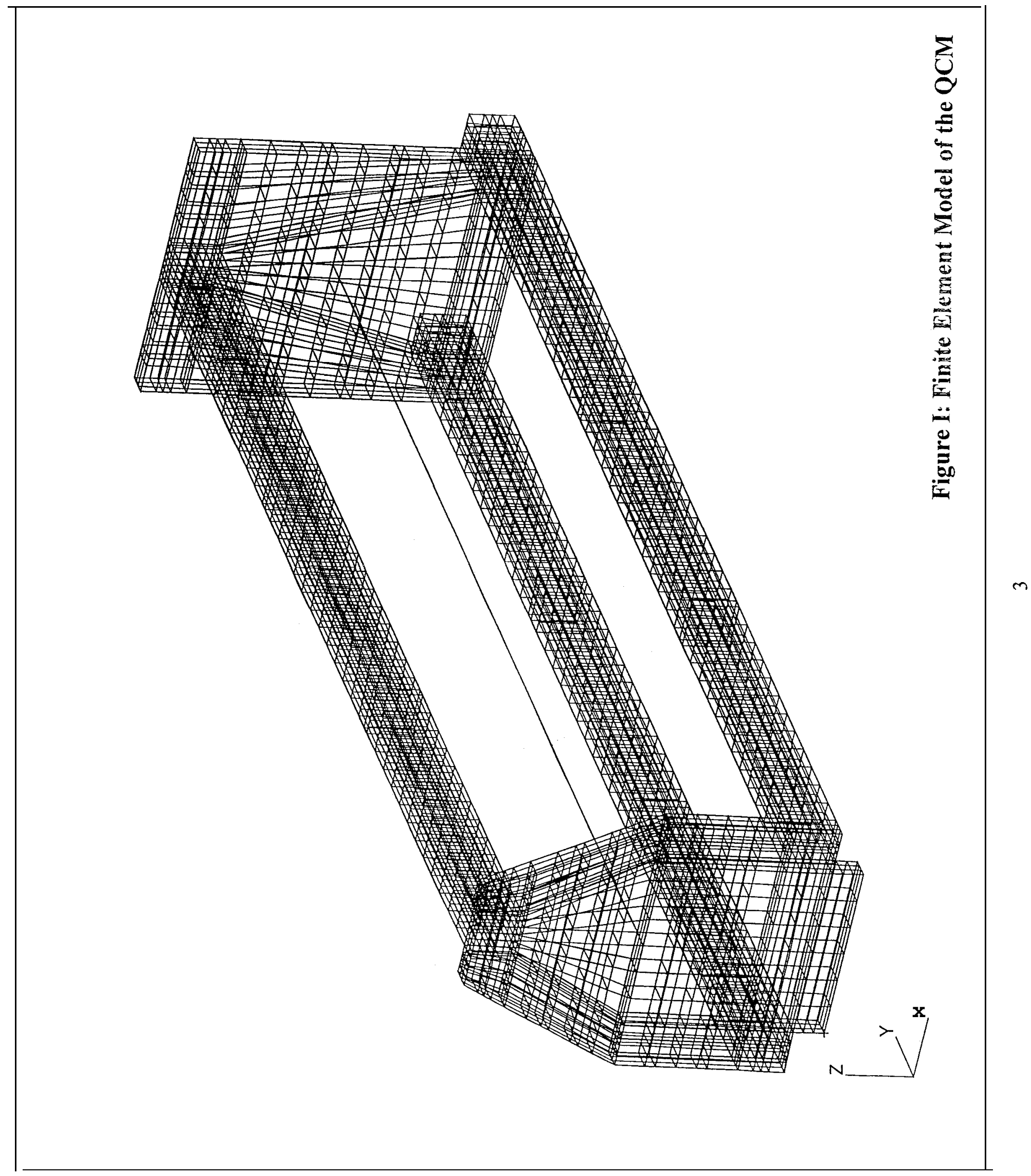




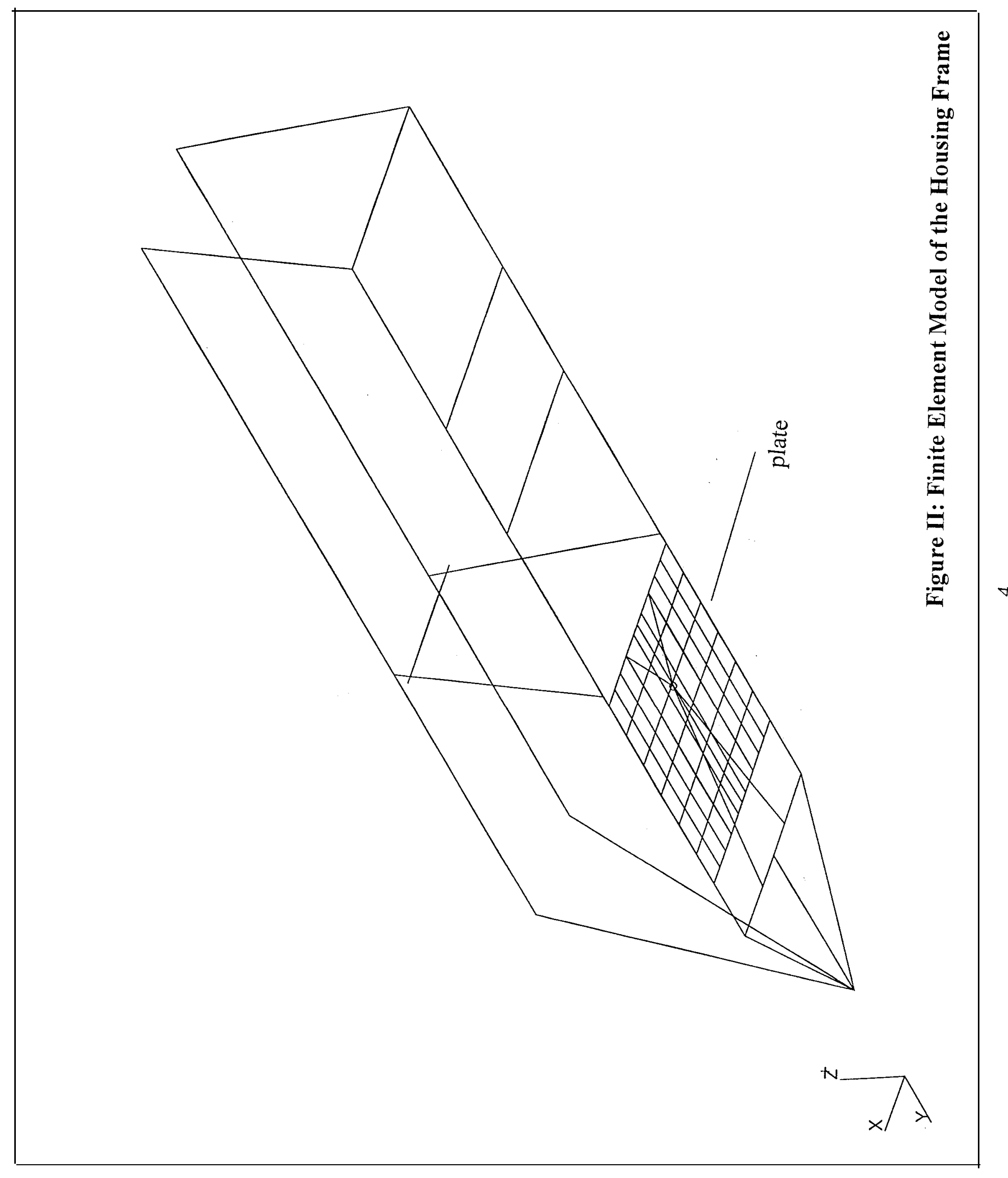




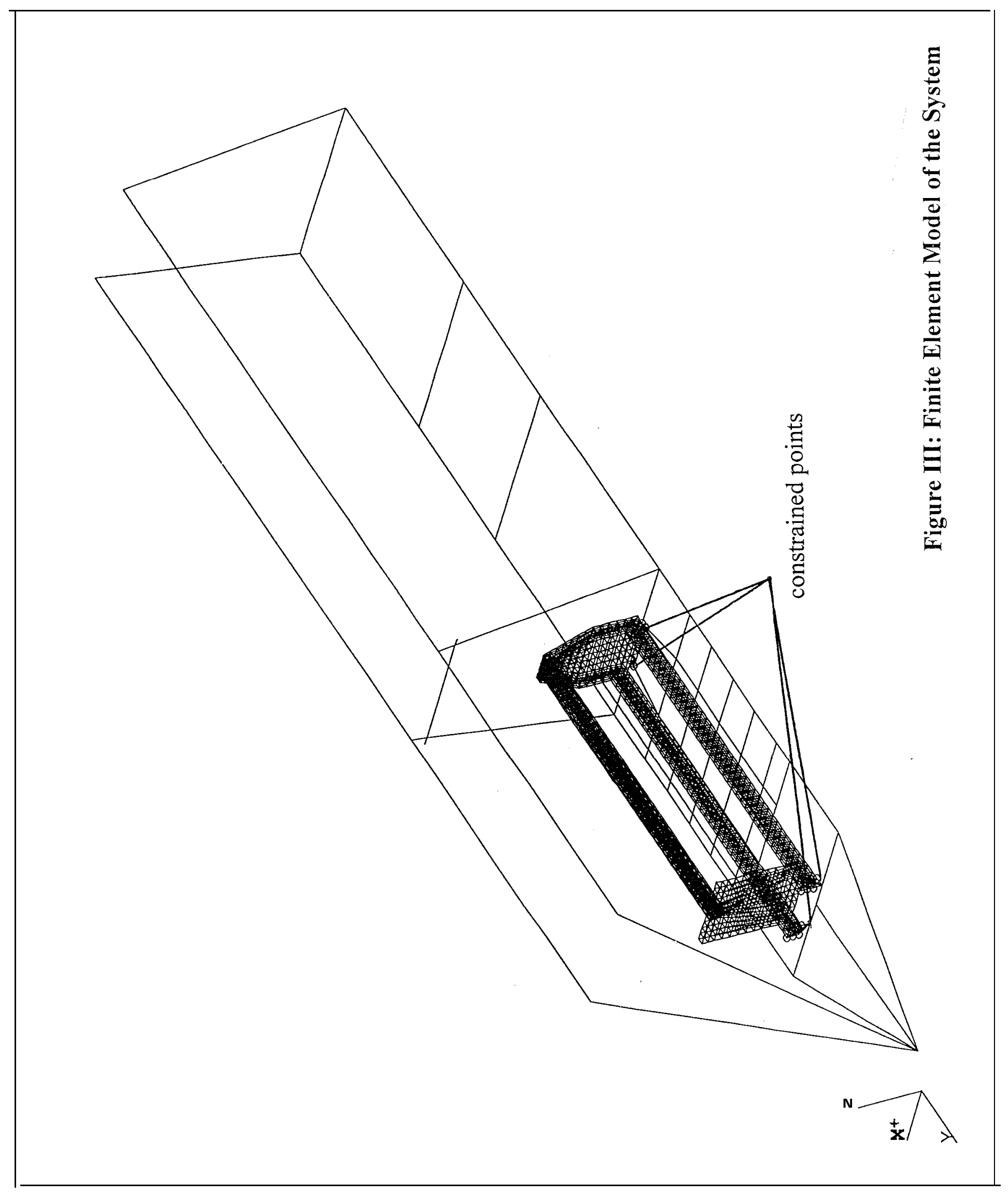




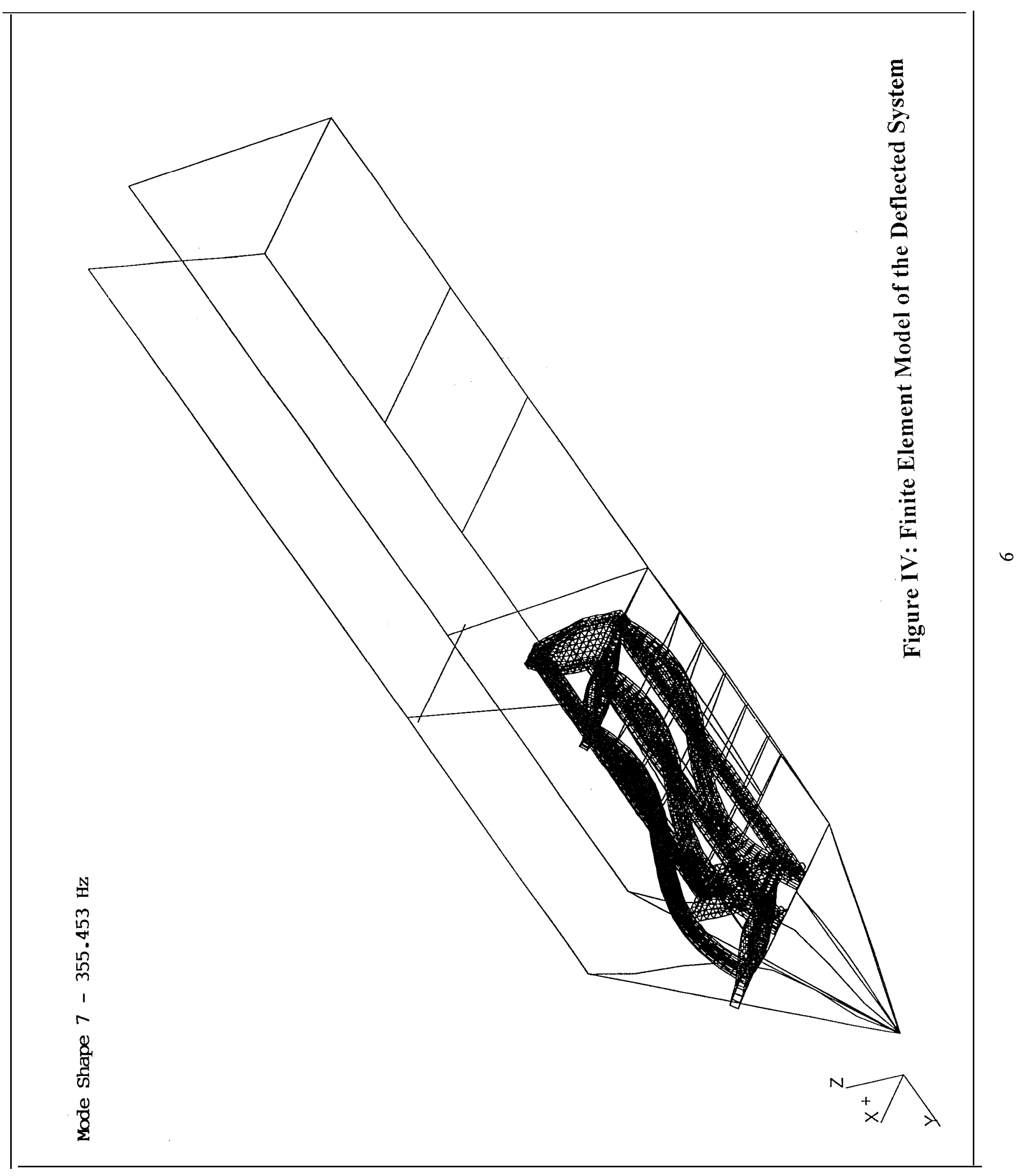

